\title{
Upregulation of microRNA-125b contributes to leukemogenesis and increases drug resistance in pediatric acute promyelocytic leukemia
}

\author{
Hua Zhang ${ }^{1 \dagger}$, Xue-Qun Luo ${ }^{2 \dagger}$, Dan-Dan Feng ${ }^{1}$, Xing-Ju Zhang ${ }^{1}$, Jun $\mathrm{Wu}^{3}$, Yu-Sheng Zheng ${ }^{1}$, Xiao $\mathrm{Chen}^{3}$, Ling Xu ${ }^{3 *}$
} and Yue-Qin Chen ${ }^{1 *}$

\begin{abstract}
Background: Although current chemotherapy regimens have remarkably improved the cure rate of pediatric acute promyelocytic leukemia (APL) over the past decade, more than $20 \%$ of patients still die of the disease, and the 5year cumulative incidence of relapse is $17 \%$. The precise gene pathways that exert critical control over the determination of cell lineage fate during the development of pediatric APL remain unclear.

Methods: In this study, we analyzed miR-125b expression in 169 pediatric acute myelogenous leukemia (AML) samples including $76 \mathrm{APL}$ samples before therapy and $38 \mathrm{APL}$ samples after therapy. The effects of enforced expression of miR-125b were evaluated in leukemic cell and drug-resistant cell lines.

Results: miR-125b is highly expressed in pediatric APL compared with other subtypes of AML and is correlated with treatment response, as well as relapse of pediatric APL. Our results further demonstrated that miR-125b could promote leukemic cell proliferation and inhibit cell apoptosis by regulating the expression of tumor suppressor BCL2-antagonist/killer 1 (Bak1). Remarkably, miR-125b was also found to be up-regulated in leukemic drug-resistant cells, and transfection of a miR-125b duplex into AML cells can increase their resistance to therapeutic drugs,
\end{abstract}

Conclusions: These findings strongly indicate that miR-125b plays an important role in the development of pediatric APL at least partially mediated by repressing BAK1 protein expression and could be a potential therapeutic target for treating pediatric APL failure.

Keywords: microRNA, pediatric acute promyelocytic leukemia (APL), treatment response, drug resistance

\section{Background}

Pediatric acute promyelocytic leukemia (APL), which represents approximately $10 \%$ of pediatric AML cases, is a subgroup of acute myelogenous leukemia (AML) characterized by promyelocytic cell morphology (referred to as M3 in the French-American-British classification) [1-3]. APL is characterized by a specific $t(15 ; 17)$ translocation that encodes a fusion of the promyelocytic leukemia (PML) and retinoic acid receptor- $\alpha$ (RARA) proteins [1-5]. Although the outcomes for children and

\footnotetext{
* Correspondence: luoxul64@yahoo.com; Isscyq@mail.sysu.edu.cn

+ Contributed equally

'Key Laboratory of Gene Engineering of the Ministry of Education, State Key Laboratory, for Biocontrol, Sun Yat-sen University, Guangzhou 510275, China ${ }^{3}$ The Second Affiliated Hospital of Sun Yat-sen University, Guangzhou, 510120, China

Full list of author information is available at the end of the article
}

adults with APL have dramatically improved since the successful introduction of all-trans retinoic acid (ATRA) in combination with anthracycline-based chemotherapy, more than $20 \%$ of patients presenting with APL will die of the disease, and the 5-year cumulative incidence of relapse is $17 \%$ overall and more than $20 \%$ in children [6-8]. The combination of ATRA and chemotherapy as initial therapy has become an attractive strategy for all APL patients; unfortunately, approximately $10 \%$ of APL patients develop "retinoic acid syndrome (RAS)" $[6,9,10]$. Furthermore, the precise genes and pathways that exert critical control over the lineage fate during APL development remain unclear.

MicroRNAs (miRNAs), a novel class of small noncoding RNAs ranging from 19 to 25 nucleotides in size, regulate specific target genes through translational 
repression or direct mRNA degradation, thereby regulating many cellular functions, including cell proliferation, differentiation, and apoptosis [11-13]. Recent studies have shown that deregulated expression of specific miRNAs that modulate expression of oncogenes and tumor suppressors is associated with the development of malignancies and that specific miRNA expression signatures can be used to effectively classify human tumors [14]. MiRNA expression signatures associated with specific cytogenetic changes and clinical outcomes of adult CLL, AML, and Hodgkin's lymphoma have been reported [15-20]. Recent data suggest that miRNA inactivation by epigenetic mechanisms plays an important role in myelopoiesis and that modulating specific miRNA levels with drugs can lead to the downregulation of target oncogenes and restoration of cell differentiation [21]. Dysregulated miRNA expression in APL cells following retinoic acid (RA) induction was also reported [22-25]. These studies, however, mainly focused on APL cell lines and included very few clinical APL samples. The role of miRNAs in the clinical progression of APL, especially in pediatric APL, remains to be explained.

Our previous study found that $m i R-125 b$ was up-regulated in pediatric primary AML using genome-wide miRNA expression profiles in 36 diagnostic acute leukemia bone marrow samples [26]. To further understand the role of $m i R-125 b$ in pediatric AML, we analyzed $m i R-125 b$ expression in 169 pediatric AML patients for whom clinical data were available. Interestingly, we found that miR-125b was reduced to normal levels in complete remission (CR) APL patients. Importantly, we found that $m i R-125 b$ could promote proliferation and inhibit apoptosis of APL cells by targeting BCL2-antagonist/killer 1 (Bak1). The results imply that $m i R-125 b$ functions as an oncogene in pediatric APL and that it has potential roles as a malignancy biomarker and a predictive marker of response to chemotherapy. In addition, we showed that transfection of the cells with $m i R-125 b$ could increase cell resistance to chemotherapeutic drugs.

\section{Methods}

Patients, sample collection, and therapeutic methods

A total of 182 pediatric samples including 131 AML samples before therapy (including 76 PML-RAR $\alpha$-positive APL samples), 38 APL samples (PML-RAR $\alpha$-positive) after therapy and 13 normal samples from the First and Second Affiliated Hospital of Sun Yat-sen University and Beijing Children's Hospital were enrolled in this study. Patients' characteristics are available for all patients (see Table 1). Bone marrow was collected from patients by bone marrow puncture at diagnosis or at follow-up after therapy. The treatment protocol for AML patients is listed in Additional file 1. Table S1. Written informed consent for the biological studies was obtained from the parent/ guardians. The study was approved by the Ethics Committee of the affiliated hospitals of Sun Yat-sen University.

\section{Cell lines and cell cultures}

Human leukemia cell line NB4, HL60, K562 and their drug resistant cell lines were maintained in RPMI 1640

Table 1 Pediatric AML patients' characteristics

\begin{tabular}{|c|c|c|c|}
\hline AML Primary $(N=131)$ & Characteristics & Median (range) & No. (\%) \\
\hline & Age at diagnosis, y & $7.8(0-14)$ & \\
\hline & Sex & & \\
\hline & Male & & $79(60.3)$ \\
\hline & Female & & $52(39.7)$ \\
\hline & WBC count, $\times 10^{9} / \mathrm{L}$ & $18.2(1.1-292)$ & \\
\hline & Less than 10 & & $76(58)$ \\
\hline & $10-50$ & & $34(26)$ \\
\hline & 50 or higher & & $21(16)$ \\
\hline & FAB & & \\
\hline & M1 & & $9(6.9)$ \\
\hline & M2 & & $27(20.6)$ \\
\hline & M3 & & $76(58)$ \\
\hline & M4 & & $5(3.8)$ \\
\hline & M5 & & $11(8.4)$ \\
\hline & M6 & & $3(2.3)$ \\
\hline \multirow[t]{2}{*}{ M3 after therapy $(\mathrm{N}=38)$} & \#CR & & $33(86.8)$ \\
\hline & \&Relapse & & $5(13.2)$ \\
\hline
\end{tabular}

AML: acute myelogenous leukemia; WBC: white blood cell; FAB: French-American-British classification; CR: complete remission. \#: CR samples are from 33 patients of 76 M3 primary patients with three years clinical follow-up;

\&: with three years clinical follow-up. 
medium containing 10\% fetal bovine serum (Gibco BRL). Drug resistant cell lines included NB4-R1 (subclones of NB4 with ATRA resistance established by ATRA inducing progressively), NB4-R2 (subclones of NB4 with ATRA resistance established by mutating the E domain of PML/ RARA), HL60/DOX (subclone of HL60 with doxorubicinresistance established by drug inducing progressively) and K562/DOX (subclone of K562 with doxorubicin-resistance established by drug inducing progressively). $293 \mathrm{~T}$ cell line was maintained in DMEM medium containing $10 \%$ fetal bovine serum (Gibco BRL).

\section{Mouse model}

Five-week-old BALB/c (nu/nu) mice were maintained under a specific pathogen-free condition in the Laboratory Animal Center, Sun Yat-sen University. All experiments were performed in accordance with our Institutional Animal Guidelines. The xenografted tumors were established by a single subcutaneous injection at the flank of ALB/c (nu/nu) mice with $2 \times 10^{6}$ HL60 cells (infected with lentivirus vectors that expressed miR-125b or miRNA negative control) in $0.1 \mathrm{ml} \mathrm{RPMI-1640} \mathrm{med-}$ ium. Each group consisted of at least 3 mice. The tumors were harvested, snap-frozen and stored at $-80^{\circ} \mathrm{C}$.

\section{RNA extraction and quantitative real-time polymerase chain reaction}

Total RNA was isolated with Trizol (Invitrogen, Carlsbad, CA) according to the manufacturer's instructions. The following two quality criteria were used to assess total RNA quality. The first is purity. Both ratios, OD A260/A280 and OD A260/A230 were in the 1.8-2.1 region. The second is integrity. Total RNA quality has been assessed by denaturing gel electrophoresis electrophoresis and the ratio of $28 \mathrm{~S}$ and $18 \mathrm{~S}$ rRNA bands was approximately 2:1. Quantitative real-time RT-PCR (qRTPCR) was performed as described [27] and employed a Hairpin-it ${ }^{\mathrm{TM}}$ miRNAs Real-Time PCR Quantization Kit containing stem-loop like RT primer, miRNA specific PCR primer and Molecular Beacon probe for $m i R-125 b$ or the U6 RNA internal control (GenePharma, Shanghai, China). The expression of miR-125b relative to that in healthy samples was calculated using the 2- $\Delta \Delta \mathrm{CT}$ method, and the expression of $\mathrm{miR}-125 \mathrm{~b}$ relative to internal control U6 RNA in mouse was calculated using the 2- $\triangle \mathrm{CT}$ method [28]. The efficiencies of PCR amplification per PCR-cycle (by a dilution curve) of both miR$125 \mathrm{~b}$ and U6 from each patient are higher than $95 \%$ (Additional file 2. Figure S1).

\section{Statistical analysis}

Fisher's exact test, paired t-test, and chi-square tests were used to compare baseline characteristics and average miRNA expression between different groups. All reported $\mathrm{P}$ values were two-sided and were obtained using SPSS software. $\mathrm{P}<0.05$ is considered significant.

\section{Target genes prediction}

Target genes prediction was performed to meet the following two criteria. First, miRNA targets were analyzed using three algorithms, including TARGETSCAN http://www.targetscan.org, PICTAR http://pictar.mdcberlin.de and miRBase http://microrna.sanger.ac.uk/ sequences/index.shtml. Second, in order to reduce the number of false positives, only putative target genes predicted by at least two of the programs were accepted.

\section{Western blotting}

Cells were homogenized in a lysis buffer (25 mM Tris$\mathrm{HCl}$ (pH 7.4), 0.5 mM EDTA, 0.5 mM EGTA, $1 \mathrm{mM}$ PMSF, $25 \mu \mathrm{g} / \mathrm{ml}$ leupeptin, $1 \mathrm{mM}$ DTT, 0.5\% Triton X100) and centrifuged. Samples of supernatant, each containing $10 \mu \mathrm{g}$ of total protein, were electrophoresed in a $5-15 \%$ gradient gel. Western blotting was performed as following. In brief, the proteins were transferred to polyvinylidene difluoride (PVDF) membranes. The membranes were blocked in $4 \%$ non-fat dry milk in Trisbuffered saline containing $0.1 \%$ Tween 20 (TBST) for 1 $\mathrm{hr}$ at room temperature and then probed overnight with rabbit polyclonal anti-Bak1 antibody (Sigma) in the same buffer. After three washes with TBST, the membranes were incubated for $1 \mathrm{hr}$ with goat anti-rabbit IgG antibody (Sigma) conjugated to horseradish peroxidase (HRP). After washing with TBST, the membranes were exposed to a chemiluminescent reagent (ECL Plus, Amersham) for $1 \mathrm{~min}$ and then to Kodak X-ray film. Anti- $\beta$-actin antibody and anti-tublin antibody (Cell signaling technology) has been used to detect beta-actin and tublin.

\section{MiR-125b expression vector construct}

Full-length double-stranded human pre-miR-125b, together with $305 \mathrm{bp}$ of flanking sequence was amplified from human genomic DNA using PCR (primer information is available in Additional file 3. Table S2) and cloned into the pcDNA ${ }^{\mathrm{TM}} 6.2-\mathrm{GW} / \mathrm{EmGFP}$-miR control vector (Invitrogen) to generate the $m i R-125 b$ expression construct pcDNA-miR-125b. The PCR product was also cloned into pIRES2-EGFP (Invitrogen, Carlsbad, CA, USA) and the fragment containing CMV promoter and $m i R-125 b$ precursor was then cloned into pINCO retroviral vector (Genechem, Shanghai, China) to generate lvmiR-125b. Insertions were verified by DNA sequencing.

\section{pGL3-BAK1 reporter construct and mutagenesis}

The 252 bp 3'-untranslated terminal region (UTR) segment of Bak1 was amplified by PCR from human 
genomic DNA and inserted into the pGL3-control vector (Promega) using the XbaI site immediately downstream from the stop codon of luciferase for $m i R-125 b$ functional analysis. Similarly, recombinant pGL3 reporter vectors for other selected possible targets were constructed. The Bak1 mutant, pGL3-BAK1-M, which had 8 bp deleted from the site of perfect complementarity to $m i R-125 b$, was generated using PCR deletion Wild-type and mutant insertions were confirmed by DNA sequencing. Primer information is available in Additional file 3. Table S2.

\section{Luciferase assay}

$0.2 \mu \mathrm{g}$ of pcDNA-miR-125b or pcDNA-control was cotransfected to $293 \mathrm{~T}$ cells with $0.1 \mu \mathrm{g}$ of pGL3-control or recombinant pGL3 reporter vector and $0.1 \mu \mathrm{g}$ of the control vector $\mathrm{pRL}-\mathrm{TK}$ containing Renilla luciferase and TK promoter (Promega) using lipofectamine 2000 (Invitrogen). For NB4 cells, $5 \mu \mathrm{g}$ of pcDNA-miR-125b or pcDNA-control, $5 \mu \mathrm{g}$ of pGL3-control or pGL3-BAK1 or pGL3-BAK1-M Firefly luciferase report vector and $2.5 \mu \mathrm{g}$ of the control vector pRL-TK were cotransfected using electroporation. $293 \mathrm{~T}$ cells or NB4 cells were grown in 24 -well plates $\left(1 \times 10^{5}\right.$ cells/well $)$ in $10 \%$ FBS in DMEM or RPMI-1640 supplemented with sodium pyruvate at $37^{\circ} \mathrm{C}$ in a humidified atmosphere of $5 \% \mathrm{CO}_{2}$. Firefly and Renilla luciferase activities were measured consecutively using dual-luciferase assays (Promega) 24 hrs after transfection, according to the manufacturers' instructions.

\section{Cell proliferation and apoptosis assay}

NB4 cells, HL60 cells, NB4-R1 cells, NB4-R2 cells and HL60/DOX cells $\left(1 \times 10^{4}\right.$ per well $)$ were plated in 96 well plates in RPMI medium 1640 and 10\% FBS that was supplemented with sodium pyruvate at $37^{\circ} \mathrm{C}$ in a humidified atmosphere of $5 \% \mathrm{CO}_{2}$. Cells were transfected with $100 \mathrm{nM} m i R-125 b$ duplex (Ambion), scrambled duplex (negative control, Ambion), or 200 $\mathrm{nM} m i R-125 b$ antisense (Ambion) using lipofectamine 2000 (Invitrogen). After culturing for 1, 2 or 3 days, the MTT assay (Promega) or CCK- 8 assay (Dojindo Molecular Technologies) was carried out to analyze cell proliferation. For apoptosis, forty-eight hours following the transfection, cells were labeled with Annexin V/PI (MultiSciences Biotech) and analyzed by flow cytometry.

\section{Cell cytotoxicity assay}

HL60 or HL60/DOX cells were seeded in 24-well plates at a density of $3 \times 10^{5}$ cells per well and transfected with 100 pmol scrambled duplex, miR-125b duplex or $m i R-125 b$ antisense, or scrambled duplex (Ambion) in three independent replicates, using Nenon transfection equipment (Invitrogen) according to the manufacturer's protocol with program settings of $1400 \mathrm{~V}, 10 \mathrm{~ms}$ width, and 3 pulses. Forty-eight hours after transfection, cells were reseeded in 96-well plates at a density of $1.5 \times 10^{4}$ per well in the presence of $m i R-125 b$ and treated with doxorubicin at a range of concentrations (5 to $25 \mu \mathrm{g}$ / $\mathrm{ml}$ ) in medium for $72 \mathrm{hrs}$. Cell survival was analyzed using the Cell Titer 96 Aqueous One Solution Cell Proliferation Assay (Promega).

\section{Results}

miR-125b is highly expressed in pediatric APL

Using genome-wide miRNA expression profiles in 36 diagnostic acute leukemia bone marrow samples, we previously identified 17 up-regulated and 18 down-regulated miRNAs that were significantly deregulated in pediatric primary AML compared with healthy samples [26]. Remarkably, $m i R-125 b$ was significantly up-regulated in pediatric APL patients compared with other AML subtypes (Figure 1A). This result was further confirmed by northern blot (Figure 1B). This finding raised the possibility that $m i R-125 b$ might play an important role in the development of pediatric APL.

To clarify the differential expression pattern of $m i R$ $125 b$, we performed large-scale qRT-PCR assays on bone marrow samples from 131 pediatric primary AML samples, including 76 APL patients with PML-RAR $\alpha$ positive APL and 55 patients with other subtypes (M1, M2, M4, M5, M6). As shown in Figure 1C, miR-125b showed exceptionally high expression in APL (average of 760 -fold higher than the normal population), although $m i R-125 b$ expression in other subtypes was also higher than normal. However, the expression of $m i R-125 b$ was not significantly different between younger (less than 10 years of age) and older (between 10 and 14 years of age) pediatric patients (Figure $2 \mathrm{~A}$ ). Our results suggested that $m i R-125 b$ might be involved in APL pathogenesis and that it might be used as a biomarker for malignancy in pediatric APL.

\section{Induction therapy suppresses miR-125b expression in pediatric APL}

All pediatric APL (M3 subtype) patients received a substantially distinct therapy utilizing the modified PETHEMA protocol (Additional file 1. Table S1) after diagnosis. We then collected 33 matched-pair APL samples at diagnosis and complete remission (CR) with PML-RAR $\alpha$-positive and with three years of clinical follow-up. We also collected 5 relapsed patients for comparison. To establish the relevance of $m i R-125 b$ expression before and after therapy treatment, we investigated $m i R-125 b$ expression in pairs of samples with diagnosis-CR or diagnosis-relapse. The results showed that in all CR patients, $m i R-125 b$ expression decreased sharply after therapy to the same levels as in the normal controls (Figure 2B), which may be due to largely 


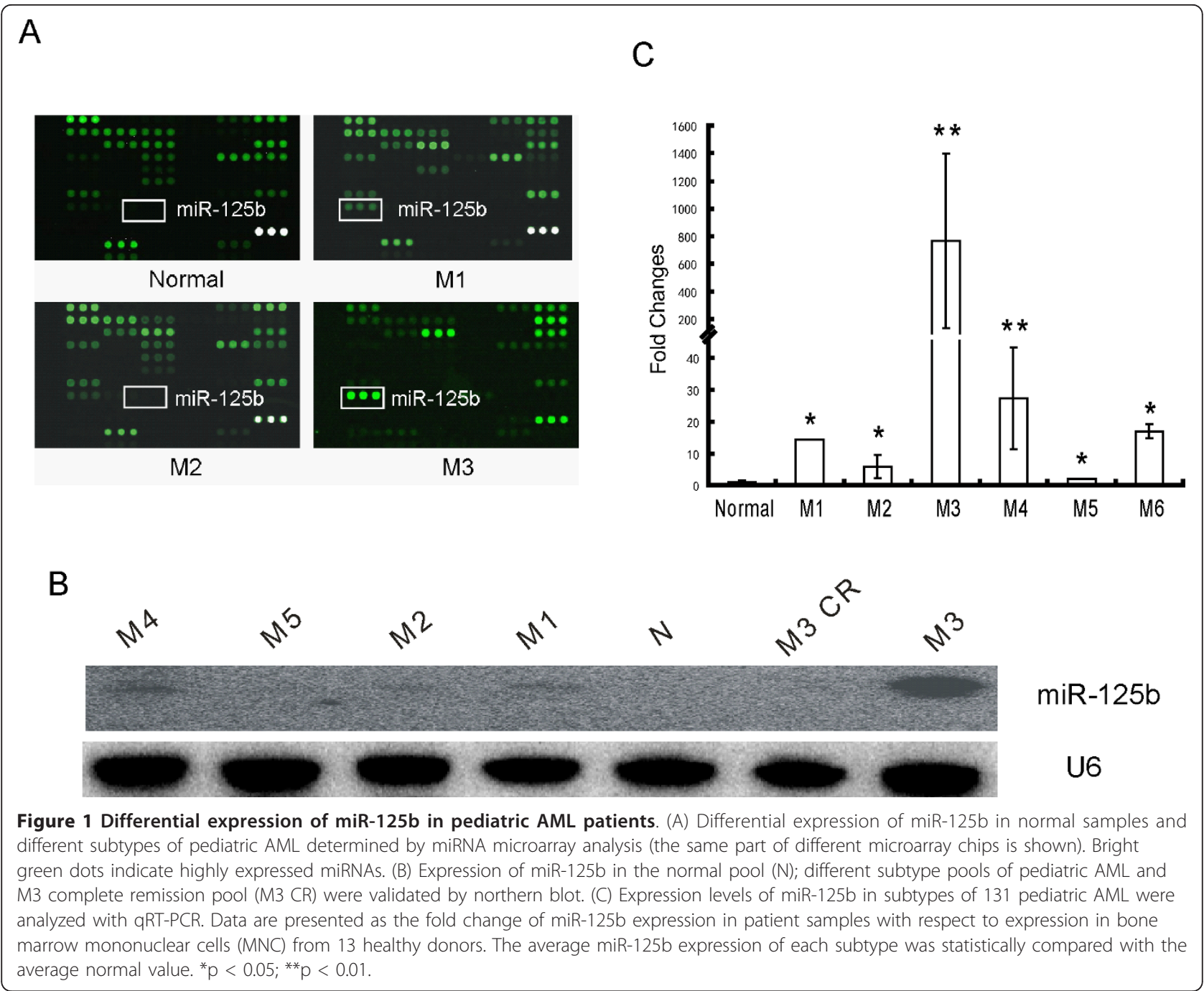

reduced leukemic cells after therapy. However, the expression level in the relapse patients was higher than normal controls, although induction therapy suppressed $m i R-125 b$ expression in these patients to some degree (Figure 2C). The significantly different expression of $m i R-125 b$ between pediatric primary, CR and relapse patients suggested that miR-125b could be a biomarker for clinical outcome. This possibility will be further studied using a larger number of patients. This finding raised the possibility that miR-125b, which is involved in the timing of tissue development and cell differentiation [29], might function as an oncogene in pediatric APL.

miR-125b represses endogenous Bak1 protein in myeloid cell lines and pediatric APL samples and is associated with disease development and treatment outcomes Elucidating the targets of miRNAs is still a major part of the miRNA functional investigation. We selected 15 potential targets that contain the conserved miRNA response elements (MREs) of miR-125b in their 3' UTR and had been reported to be related to leukemogenesis for further experimental investigation. Among them, we confirmed that four putative targets (BAK1, MAP3K10, MCL1, and TRIAP1) were repressed by $m i R-125 b$ when transfected to $293 \mathrm{~T}$ cells, with a repression rate of more than $25 \%$, as measured by a luciferase assay (Additional file 4. Figure S2A). Remarkably, we found that the tumor suppressor Bak1 had the most reduced activity, which suggested that Bak1 was likely to be an important target regulated by miR-125b in leukemia. To further test our hypothesis, we constructed a recombinant pGL3-BAK1-M with a mutant miR-125b binding site (Figure 3A). pGL3-BAK1 and pGL3-BAK1-M were then cotransfected into NB4 cells either with or without pcDNA-miR-125b using the electroporation method. As shown in Figure 3B, transfection of miR-125b reduced 
A

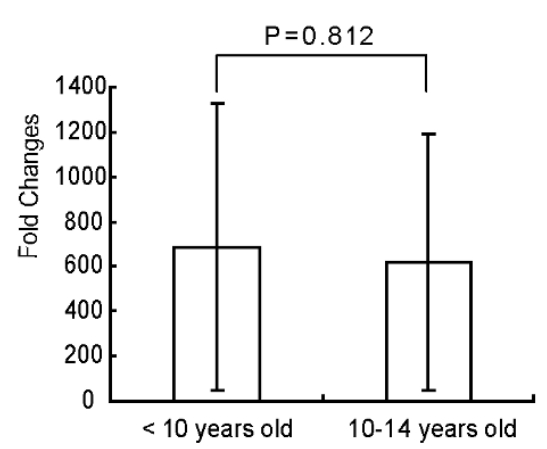

B

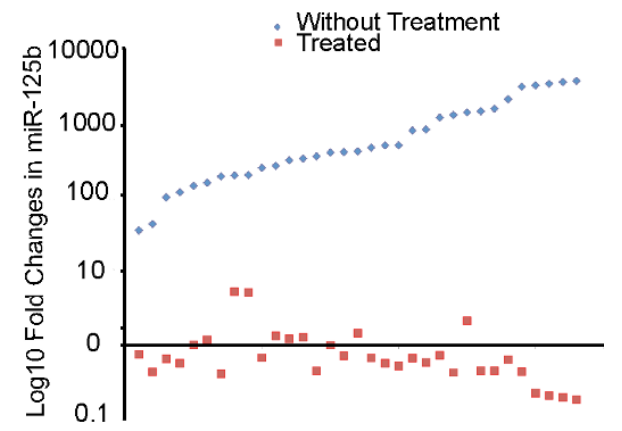

C



Figure 2 Expression of miR-125b varied in different therapeutic response groups of pediatric APL. The gRT-PCR assay was repeated three times, and similar results were obtained. Representative results are shown as means \pm standard deviation $(\mathrm{M} \pm \mathrm{SD})$. Data presented are the fold changes of expression with respect to the bone marrow MNC from five healthy donors. (A) Expression level of miR-125b in different age groups of pediatric APL patients. (B) The expression levels of miR-125b in 33 pediatric APL patients before and after therapy are presented as fold changes of expression with respect to expression in bone marrow mononuclear cells (MNC) from healthy donors. MiR-125b levels for the same patient before and after therapy were paired. Data were sorted from lowest to highest levels of miR-125b in non-treated patients. (C) Expression level of miR-125b in pediatric APL patients before and after therapy. ${ }^{*} p<0.05,{ }^{* *} p<0.01$.

luciferase activity in pGL3-BAK1 transfected NB4 cells by about $40 \%$. However, in NB4 cells transfected with either wild-type or mutant reporter in the absence of pcDNA-miR-125b, there was almost no change in luciferase activity. This finding demonstrates that Bak1 is a target of $m i R-125 b$ in leukemic cells and that the putative $m i R-125 b$ binding site is critical for $m i R-125 b$ regulation of Bak1 expression.

To further investigate whether overexpression of $m i R$ $125 b$ can promote APL myeloid cell progression by targeting tumor suppressor Bak1, we transfected two APL cell lines (NB4 and HL60) with $100 \mathrm{nM} \mathrm{miR-125b}$ duplex using the electroporation method (Additional file 4. Figure S2B). Bak1 expression was strongly reduced compared with that transfected with scrambled duplex in both myeloid cell lines NB4 (Figure 3C, left panel) and HL60 (Figure 3C, right panel). To uncover the effects of suppression in vivo, HL60 cells were infected with lentivirus vectors that expressed miR-125b (lv-miR$125 \mathrm{~b})$ or miRNA negative control (lv-NC), and then transplanted into nude mice with SC injection. Both groups of mice transplanted with lv-miR-125b-HL60 cells and lv-NC-HL60 cells developed solid tumors three weeks later. The overexpression of miR-125b was examined using qRT-PCR (Figure 3D, upper). The western blot analysis showed the Bak1 protein was repressed in the lv-miR-125b-HL60 tumors compared with the lvNC-HL60 tumors transplanted with miRNA negative control (Figure 3D, lower).

Next, to examine the possibility that Bak1 was also regulated by $m i R-125 b$ in clinical samples, we measured the expression levels of these two molecules in 47 pediatric APL clinical samples (only 47 samples have enough proteins to be used for western blot ananlysis) and five normal donors. We found that the levels of Bak1 and miR$125 b$ were inversely correlated in $70.2 \%(33 / 47)$ of the pediatric APL samples (Figure 3E). For comparison, Figure $3 \mathrm{~F}$ illustrates typical Bak1 protein expression in the 33 samples with the highest $\left(\mathrm{APL}_{\mathrm{H}}\right)$ and lowest $\left(\mathrm{APL}_{\mathrm{L}}\right)$ levels of expressed miR-125b. The levels of miR-125b expression for $\mathrm{APL}_{\mathrm{H}}$ and $A P L_{L}$ were 80,071-fold and 10.24-fold higher than the normal average, respectively, while the levels of Bak1 expression were 50-fold lower in $\mathrm{APL}_{\mathrm{H}}$ and 2-fold lower in $\mathrm{APL}_{\mathrm{L}}$. These results strongly suggest that Bak1 is a target of $m i R-125 b$ in pediatric APL.

Because induction therapy suppressed miR-125b expression in pediatric APL patients, we would expect that, as a target of $m i R-125 b$, Bak1 levels would also be affected by therapeutics. We therefore analyzed the levels of Bak1 and miR-125b in samples from follow-up patients and compared the profiles with the profiles obtained from the same patients before therapy. In addition, three normal marrows were used as controls. Bak1 expression was increased in about $60 \%$ of CR patients $(19 / 33)$ receiving therapeutics (Figure 3G). Thus, a concordant negative correlation existed between $m i R-125 b$ levels and Bak1 levels with respect to disease development and treatment outcome. 


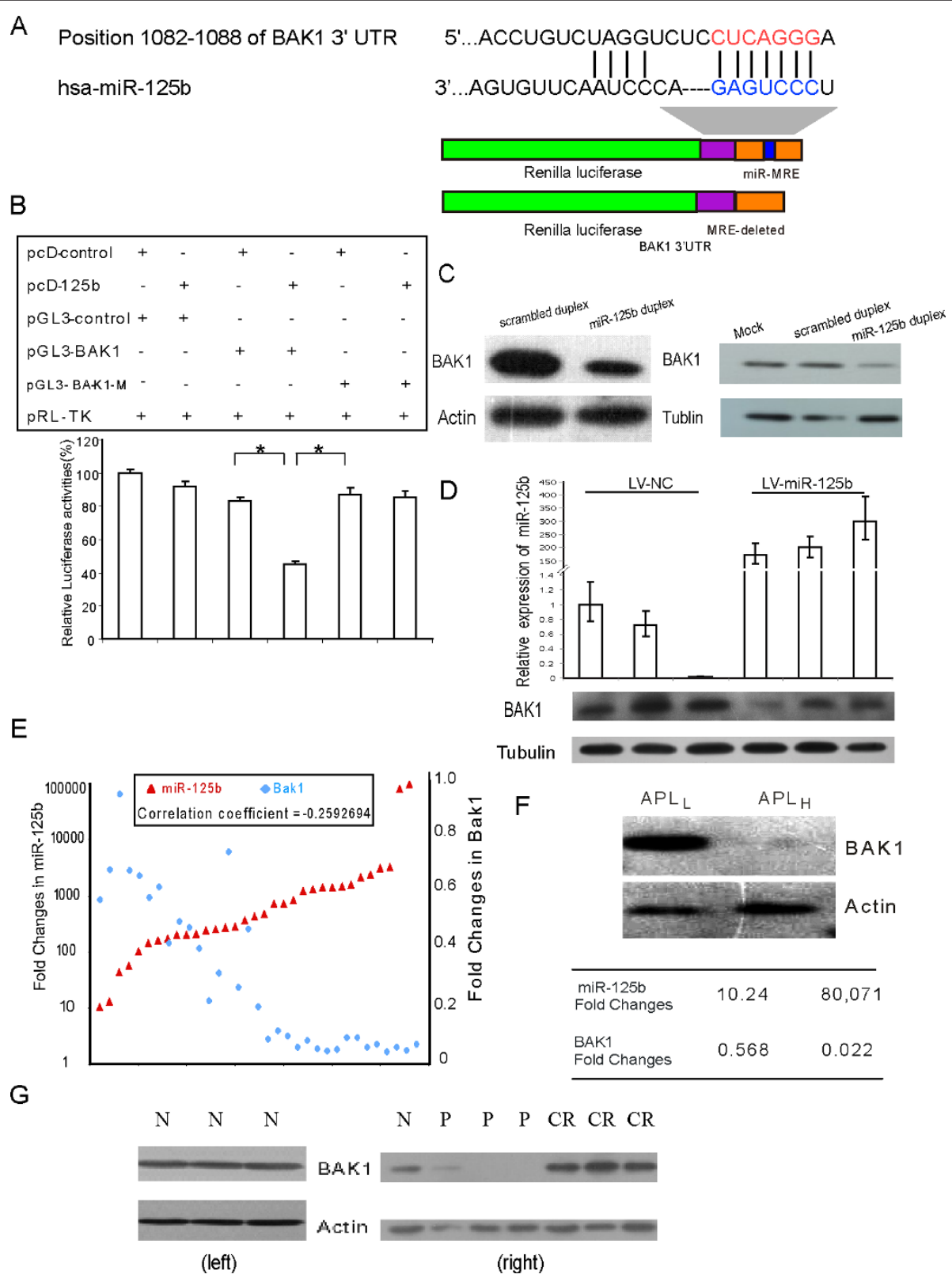

Figure 3 Exogenous miR-125b deregulates Bak1 protein. (A) An outline of luciferase reporter assay for validating the interaction of miR-125b with the 3' UTR of BAK1 is shown. Red text indicates the "seed" regions. In mutant reporter constructs, the MRE was deleted. (B) Repression of luciferase activity due to the interaction between miR-125b and the predicted MREs in the luciferase-Bak1-3' UTR constructs. The values represent the average $\pm S D(n=3) .{ }^{*} p<0.05$. (C) Western blot analysis of BAK1 expression in NB4 cells (left panel) or HL60 cells (right panel) after transfection with $100 \mathrm{nM}$ miR-125b duplex or scrambled duplex. (D) The effects of suppression of miR-125b on Bak1 in mouse model. Upper: the overexpression of miR-125b was examined using qRT-PCR; lower: western blot analysis showed the Bak1 protein was repressed by miR-125b. IvmiR-125b: lentivirus vectors that expressed miR-125b; IV-NC: lentivirus vectors that expressed miR-NC, miRNA negative control. (E) Bak1 protein expression was inversely correlated with miR-125b levels in 33 of 47 pediatric APL patient samples. Red triangle: miR-125b expression (fold change vs. normal average); light blue diamond: Bak1 protein expression (fold change vs. normal average). Both miR-125b and Bak1 average expression levels of healthy donors were set at 1. (F) Western blotting images showing typical high and low Bak1 protein expression levels. The Bak1 protein level was quantified from western blot bands normalized to the $\beta$-actin level. The average expressions of Bak1 and miR-125b, presented as fold change compared with healthy samples, are listed in the table. (G) Bak1 protein expression in three normal donors using western blot (left), selected typical Bak1 protein expression in normal donor and pediatric patients with different ATRA responses was analyzed by western blot (right). $\mathrm{N}$, normal donor; $\mathrm{P}$, samples collected in primary diagnosis without treatment; $C \mathrm{R}$, complete remission after therapy. 
Exogenous miR-125b promotes leukemic cell proliferation and inhibits apoptosis of leukemic cells

Bak1 is a pro-death protein and can promote programmed cell death [30]. Overexpression of $m i R-125 b$, which inhibits Bak1 expression, may therefore result in reduced apoptosis and enhanced proliferation of leukemic cells and further induce oncogenesis. Thus, we measured cell proliferation and viability of transfected NB4 cells using an MTT assay and CCK-8 assay. As expected, proliferation of NB4 cells was stimulated by the transfected $m i R-125 b$ duplex (Figure $4 \mathrm{~A}$ ) or lv-miR-125b (Additional file 5. Figure S3), and the effect was timedependent. In addition, transfection of HL60 cells with $100 \mathrm{nM}$ miR-125b promoted cell proliferation (Figure $4 \mathrm{~B})$. These results showed that $m i R-125 b$ may function as an oncogene and may contribute to APL progression.

A

B
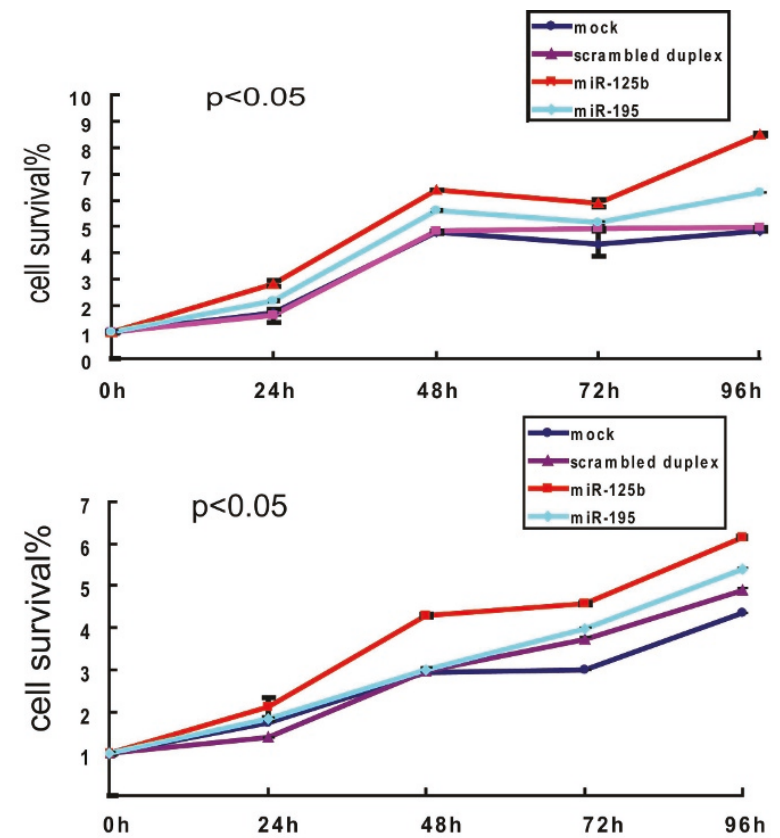

C

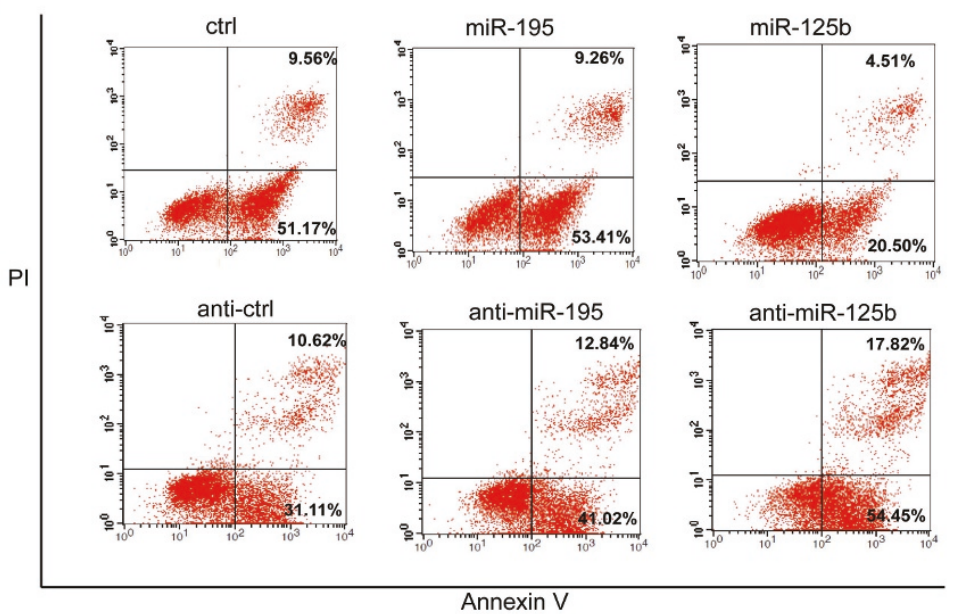

Figure 4 miR-125b promotes cell proliferation and inhibits apoptosis in leukemic cell lines NB4 and HL60. (A) Time-dependent effects of miR-125b on NB4 cell proliferation were confirmed using an MTT assay. (B) Time-dependent effects of miR-125b on HL60 cell proliferation were confirmed using an MTT assay. At least three independent experiments were performed and similar results were obtained. Data are represented as means \pm SD from 3 independent experiments. $P<0.05$, compared with mock, scrambled duplex and miR-195 at 48,72 and 96 hrs. (C) Apoptosis in a leukemic cell line transfected with miR-125b duplex, as detected by flow cytometry. Upper panel: The NB4 cells were transfected with 100 nM scrambled duplex, miR-195 or miR-125b duplex, respectively. Lower panel: The NB4 cells were transfected with 100 nM antisense control, miR-195 or miR-125b antisense, respectively. Forty-four hours following transfection, camptothecin was added to induce cells for four hours and then cells were labeled with Annexin V/PI and analyzed by flow cytometry. Three independent experiments were performed and similar results were obtained. 
We then transfected the myeloid leukemic cell line NB4 with miR-125b duplex (mimics) and miR-125b inhibitor (anti-miR-125b) to assess the possible role of $m i R-125 b$ in apoptosis in leukemic cells. However, in cancer cells, p53 and Bak1 protein are mainly localized in the cytoplasm, so the endogenous activity of Bak1 is usually insufficient to modulate apoptosis [31]. Additionally, a previous study showed that ectopic expression of $m i R-125 b$ in cells only suppresses apoptosis when the mitochondrial pathway is fully activated by exposure to the drug [32]. We then treated the cells with 7-ethyl-10-hydrol-camptothecin and performed flow cytometry assays after $48 \mathrm{hrs}$ of transfection. The results showed that ectopic expression of $m i R-125 b$ significantly suppressed 7-ethyl-10-hydrol-camptothecininduced apoptosis of NB4 cells (Annexin V-FITC positive) compared with control and miR-195 duplex (Figure 4C, upper panel).

The ability of transfection with $m i R-125 b$ antisense to control apoptosis was also examined. Interestingly, after

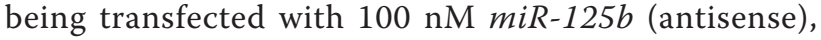
the percentage of 7-ethyl-10-hydrol-camptothecininduced apoptotic NB4 cells (ANNEXIN V-FITC positive) at 48 hrs increased compared with control and miR-195 duplex (Figure 4C, lower panel). Similar results were obtained in HL60 cells (Additional file 6. Figure S4A). These results demonstrate that transfection of $m i R-125 b$ antisense can remarkably increase cell apoptosis in leukemia cells. Furthermore, we inferred that $m i R$ $125 b$ directly regulates Bak1 expression, thereby modulating the susceptibility of leukemic cells to apoptosis.

To prove the physiological relevance of Bak1, RNAi against Bak1 was performed to analyze its role in myeloid cell apoptosis. The transfection of NB4 cells with different pieces of siRNAs against the Bak 1 mRNA resulted in greatly decreased levels of the endogenous protein Bak1, especially for the pieces si-Bak1-1, si-Bak1-2 and si-Bak13 (Figure 5A). To test if down-regulation of Bak1 was able to inhibit myeloid cell apoptosis, we detected cell apoptosis 48 hrs after transfection of NB4 cells with siBak1-3 and a mixture of the three strands of siRNA. The number of apoptotic leukemic cells was obviously reduced by the subsequent downregulation of Bak1 (Figure 5B-D). Altogether, these data indicate that the artificial increase of $m i R-125 b$ or reduction of Bak1 levels was able to inhibit myeloid leukemic cell apoptosis.

\section{Up-regulation of miR-125b levels was found in resistant cells and reduction of the expression levels increased their sensitivity to therapeutic drugs}

We noted above that the expression of $m i R-125 b$ in all $\mathrm{CR}$ patients normalized after therapy, while it remained much higher in relapse patients (Figure 2C). We also found that $m i R-125 b$ expression was slightly up-regulated in four drug-resistant cell lines, including HL60/
DOX, K562/DOX (subclone of K562 with doxorubicinresistance) and NB4-R1, as well as NB4-R2 (subclones of NB4 with ATRA resistance), when compared with their drug-sensitive parental cells (Figure 5E). These findings imply that $m i R-125 b$ contributes to the drugresistant nature of leukemic cells and that up-regulation of $m i R-125 b$ levels in cells may increase their resistance to therapeutic drugs.

To address this issue, we transfected drug-resistant HL60/DOX cells and NB4-R1 with miR-125b duplex. Transfection of HL60/DOX cells with $m i R-125 b$ duplex increased their resistance to DOX treatment. The IC50 of HL60/DOX cells transfected with miR-125b duplex was higher $(\mathrm{p}<0.05)$ compared with the IC50 for HL60/DOX cells transfected with the miRNA duplex control and miR-195 duplex (Figure 5F). We also reproduced the same experiment in NB4-R1, and the results are shown in Additional file 6. Figure S4B. Taken together, the above results indicate a link between miR$125 b$ dysregulation and drug resistance. However, the precise pathway and mechanism of action of $m i R-125 b$ in the acquisition of drug resistance remains elusive.

\section{Discussion}

In our previous investigation, we analyzed genome-wide miRNA expression profiles in pediatric AML and identified miRNA patterns specific to this disease. We also found that unique miRNA expression profiles were present in different subtypes of AML [26]. These results imply that particular miRNAs might have specific roles in carcinogenesis or in the development of certain subtypes of leukemia. We noted that the expression of some miRNAs, including miR-125, was strikingly higher in pediatric APL than other subtypes of AML. This phenomenon led us to consider whether these miRNAs are oncogenic, whether they cause specific subtypes of pediatric leukemia or simply accompany them, or, alternatively, whether they represent a tumor suppressor feedback mechanism that is superseded by malignancy. Elucidating these questions should enhance our understanding of the malignant progression of pediatric APL. Therefore, to address these questions, we focused on the role of highly up-regulated $m i R-125 b$ in pediatric APL.

The expression of $m i R-125 b$ has been investigated in many human cancers. It is down-regulated in human breast cancer, thyroid anaplastic carcinomas, ovarian cancer, squamous cell carcinoma of the tongue, and hepatocellular carcinoma, suggesting that it functions as a tumor suppressor [33-38]. Myeloid cell differentiation arrest by $m i R-125 b$ was also found in leukemia. M. Bousquet et al. demonstrated that $m i R-125 b$ was able to interfere with primary human CD34+ cell differentiation and overexpression of $m i R-125 b$ is sufficient both to 


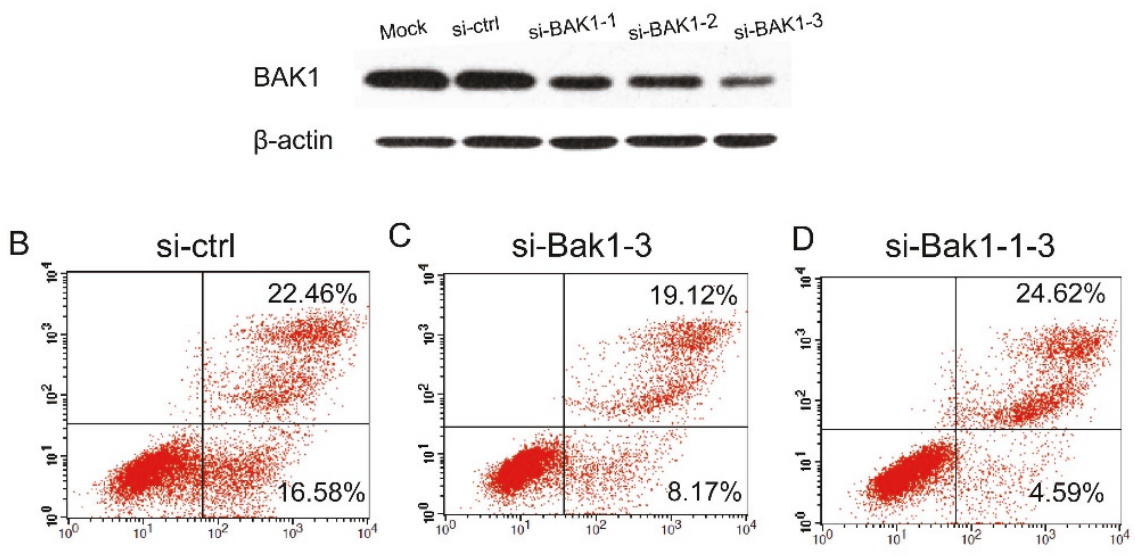

$E$

$\mathrm{F}$


Figure 5 Apoptosis after knockdown of Bak1 and the involvement of miR-125b in drug-resistant leukemic cells. (A) Western blotting images showing low Bak1 protein expression when NB4 cells were transfected with three different strands of si-RNA of Bak1. (B), (C) and (D) The NB4 cells were transfected with 100 nM si-RNA control, a strand of si-Bak1-3 or a mixture of these three strands of si-Bak. Forty-eight hours following transfection, camptothecin was added and cells were labeled with Annexin V/PI and analyzed by flow cytometry. Three independent experiments were performed and similar results were obtained. (E) miR-125b expression was up-regulated in drug-resistant cell lines compared to their drug-sensitive parental cells. ${ }^{*} p<0.05$ compared with corresponding parents cells. (F) Transfection of HL60/DOX cells with miR-125b duplex increases their resistance to DOX treatment. The $I_{50}$ of HL60/DOX cells transfected with miR-125b duplex was higher $(p<0.05)$ compared with the $\mathrm{IC}_{50}$ for HL60/DOX cells transfected with miRNA duplex control and miR-195. Three independent experiments were performed.

shorten the latency of BCR-ABL-induced leukemia and to independently induce leukemia in a mouse model $[39,40]$. These results reveal that miR-125b is important in cancer development.
The most important finding of this study was the discovery that miR-125b levels are related to the treatment response in pediatric APL patients. In patients with APL and positive PML-RAR $\alpha$ gene fusion, miR-125b 
expression was much higher than in patients with other subtypes of AML, suggesting that miR-125b may be involved in $P M L / R A R A$-positive pediatric APL patients. However, the detailed mechanism of its role remains to be characterized. Notably, we found that miR-125b expression is associated with both disease development and treatment response. These results thus suggest a potential that miR-125b may represent a suitable biomarker for predicting the effect of chemotherapy.

Shi et al. showed that in prostate cancer, upregulated miR-125b could promote proliferation and targets Bak1 $[40,41]$. Zhou et al. demonstrated that Bak1 is a direct target of $m i R-125 b$ in breast cancer [42]. However, the role of $m i R-125 b$ in leukemia, especially in pediatric APL, remains unclear. We also found an inverse correlation between levels of miR-125b and Bak1 and obtained strong evidence that miR-125b could directly inhibit Bak1 expression in pediatric APL. Taken together, these findings suggest that up-regulated $m i R-125 b$ may be part of a common regulatory pathway in different cancers. Furthermore, exogenous $m i R-125 b$ is capable of promoting proliferation of malignant cells. This finding indicates that $m i R$ $125 b$ may function as an oncogene by inhibiting APL cell apoptosis and promoting APL cell proliferation.

Although conventional therapy, such as the modified PETHEMALPA99 protocol, succeeded in obtaining long term CR in more than $70 \%$ of APL patients, early death and relapse in some patients are still a major concern in therapeutics, especially for pediatric APL. However, the mechanism of the patients' resistance to chemotherapeutic treatment is not entirely clear. Therefore, distinguishing the reason behind drug resistance and developing biomarkers are critical.

We have shown that miR-125b differentially expressed between pediatric APL primary, CR and relapse patients, suggesting a potential that high miR-125b expression might be used as a biomarker to indicate the treatment response of pediatric APL patients, although the detailed mechanism is still unknown. More importantly, transfection of NB4 and HL60 cells with miR-125b effectively inhibited apoptosis of these leukemic cells. Previously, M. Bousquet et al. reported that $m i R-125 b$ was able to block the differentiation of NB4 cells induced by ATRA [39]. Recently, miR-125b was also found associated with drug resistance in breast cancer and pediatric acute lymphoblastic leukemia $[42,43]$. In this study, we also demonstrated that up-regulation of $m i R-125 b$ in pediatric APL cells can increase their resistance to therapeutic drugs. We speculated that increased miR-125b expression might block the differentiation of hematopoietic precursors and respond to induction by ATRA or other chemotherapeutic drugs.

The expression of miR-125b both in pediatric and adult leukemia is currently not well understood. In adult APL,

M. Bousquet et al. showed that myelodysplastic syndrome and AML patients carrying the $\mathrm{t}(2 ; 11)(\mathrm{p} 21 ; \mathrm{q} 23)$ translocation were associated with $m i R-125 b$ up-regulation [39]; however, they only studied 19 adult leukemia patients carrying the $\mathrm{t}(2 ; 11)(\mathrm{p} 21 ; \mathrm{q} 23)$ translocation and did not determine whether the expression of $m i R-125 b$ was up-regulated in adult APL patients. Another miRNA expression profiling assay suggested that $m i R-125 b$ was up-regulated in seven adult APL patients, but this was not validated [44]. Thus, miR-125b expression should be further examined on a large scale with adult APL patients. Remarkably, in our large-scale qRT-PCR assay using 131 pediatric primary AML samples (M1 to M6), we found that $m i R-125 b$ was exceptionally highly expressed in the pediatric APL subtype compared with other AML subtypes. Because pediatric AML is a heterogeneous disease made up of various leukemia subtypes that differ markedly in their cytogenetics, the identification of these specific cytogenetic characteristics within each subtype will be helpful for elucidating the mechanism of oncogenesis in particular AML subtypes. Furthermore, this information may benefit the design of chemotherapeutic strategies for patients.

In conclusion, this is the first study of $m i R-125 b$ expression in pediatric APL patients. Our results suggest that miR-125b might be used as a biomarker of malignancy and as a biomarker to evaluate the effectiveness of chemotherapy in pediatric APL. We also found that $m i R-125 b$ promots proliferation and inhibits cell apoptosis at least partially mediated by targeting tumor suppressor Bak1 in pediatric APL. More importantly, forcing expression of $m i R-125 b$ can increase resistance to therapeutic drugs, suggesting that $m i R-125 b$ is a potential therapeutic target for pediatric APL failure.

\section{Additional material}

\section{Additional file 1: Table S1. AML treatment protocol}

Additional file 2: Figure S1. The efficiencies of PCR amplification of miR-125b and U6. The efficiencies of PCR amplification of both miR125b (A) and U6 (B) from the same patient are higher than 95\%. A tenfold dilution of total RNA was used from $100 \mathrm{ng}$ to $0.01 \mathrm{ng}$.

Additional file 3: Table S2. Primers information

Additional file 4: Figure S2. Luciferase reporter assay analyzed the targets of miR-125b and miR-125b expression level in HL60 cells after transfection using the electroporation method. (A) Luciferase activity was decreased because the $3^{\prime}$ UTR of BAK1, MAP3K, MCL1 and TRIAP1 was binding to miR-125b. (B) miR-125b expression level in HL60 cells was measured by qRT-PCR analysis after transfection with miRNA scrambled duplex, miR-125b mimics, miRNA inhibitor negative control and miR-125b inhibitor. Error bars represent standard deviation and were obtained from three independent experiments.

Additional file 5: Figure S3. miR-125b promotes cell proliferation in NB4. (A) The qRT-PCR assay was used to measure expression profiles of miR-125b. Data presented are the fold changes of miR-125b in NB4 cells transduced with IV-miR-125b and IV-Src; (B) Cell proliferation was detected using CCK-8 assay. NB4, NB4-miR-125b and NB4-Scr cells with 
different expression profiles of miR-125b were induced by 1 uM ATRA and cell proliferation was measured at $24 \mathrm{hrs}, 48 \mathrm{hrs}$ and $72 \mathrm{hrs} .{ }^{*} \mathrm{p}<$ 0.05 compared with mock (NB4) and NB4-Scr.

Additional file 6: Figure S4. miR-125b inhibits apoptosis in HL60 cells and increases NB4-R1 cells resistance to ATRA treatment. (A) The HL60 cells were transfected with $100 \mathrm{nM}$ antisense control or miR$125 \mathrm{~b}$ antisense, respectively. Forty-four hours following transfection, camptothecin was added to induce cells for four hours and then cells were labeled with Annexin V/PI and analyzed by flow cytometry. Three independent experiments were performed and similar results were obtained. (B) Transfection of NB4-R1 cells with miR-125b duplex increases their resistance to ATRA treatment. Three independent experiments were performed.

\section{Acknowledgements}

The authors would like to thank the following investigators and hospitals that provided samples for the analysis: Dr. Hai-Xia Guo at the Second Affiliated Hospital of Sun Yat-sen University; Li-Bing Huang at the First Affiliated Hospital of Sun Yat-sen University; and Li-Ming Tu Guangdong at the Provincial People's Hospital. We thank Dr. ShaiJuan Chen for kindly providing the NB4-R1, NB4-R2 cell lines. This work was supported by the National Science and Technology Department (2011CB811301, 2011 CBA01105 and 2009ZX09103-641) and National Natural Science Foundation of China (No. 30672254, 30872784 and 30772366)

\section{Author details}

'Key Laboratory of Gene Engineering of the Ministry of Education, State Key Laboratory, for Biocontrol, Sun Yat-sen University, Guangzhou 510275, China. ${ }^{2}$ The First Affiliated Hospital of Sun Yat-sen University, Guangzhou, 510080, China. ${ }^{3}$ The Second Affiliated Hospital of Sun Yat-sen University, Guangzhou, 510120, China.

\section{Authors' contributions}

$\mathrm{HZ}$, and XQL contributed equally to this work, performing experiments, analyzing the data, and writing the manuscript; DDF, YSZ, XJZ and JW performed and analyzed western blot and QRT-PCR data; ZGL, XC, and ZYK provided patient samples and clinical data and designed the experiments; LX and YQC designed experiments and edited the manuscript. All authors critically read and approved the final manuscript.

\section{Competing interests}

The authors declare that they have no competing interests.

Received: 14 April 2011 Accepted: 1 September 2011

Published: 1 September 2011

\section{References}

1. Bennett JM, Catovsky D, Daniel MT, Flandrin G, Galton DA, Gralnick HR, Sultan C: Proposals for the classification of the acute leukemias. FrenchAmerican-British (FAB) co-operative group. Br J Haematol 1976, 33:451-458[http://www.ncbi.nlm.nih.gov/pubmed/188440].

2. Bennett JM, Catovsky D, Daniel MT, Flandrin G, Galton DA, Gralnick HR, Sultan C: A variant form of hypergranular promyelocytic leukemia (M3). Ann Intern Med 1980, 92:280-288[http://www.ncbi.nlm.nih.gov/pubmed/ 7352737].

3. Murthy R, Vemuganti GK, Honavar SG, Naik M, Reddy V: Extramedullary leukemia in children presenting with proptosis. J Hematol Oncol 2009, 2:4 [http://www.ncbi.nlm.nih.gov/pubmed/19166619].

4. de Thé H, Lavau C, Marchio A, Chomienne C, Degos L, Dejean A: The PMLRAR alpha fusion mRNA generated by the $t(15 ; 17)$ translocation in acute promyelocytic leukemia encodes a functionally altered RAR. Cell 1991, 66:675-686[http://www.cell.com/retrieve/pii/009286749190113D].

5. Kakizuka A, Miller WH Jr, Umesono K, Warrell RP Jr, Frankel SR, Murty W, Dmitrovsky E, Evans RM: Chromosomal translocation $t(15 ; 17)$ in human acute promyelocytic leukemia fuses RAR alpha with a novel putative transcription factor, PML. Cell 1991, 66:663-674[http://www.cell.com/ retrieve/pii/009286749190112C].
6. Tallman MS, Nabhan C, Feusner JH, Rowe JM: Acute promyelocytic leukemia: evolving therapeutic strategies. Blood 2002, 99:759-767[http:// www.ncbi.nlm.nih.gov/pubmed/11806975].

7. Ortega JJ, Madero L, Martín G, Verdeguer A, García P, Parody R, Fuster J, Molines A, Novo A, Debén G, Rodríguez A, Conde E, de la Serna J, Allegue MJ, Capote FJ, González JD, Bolufer P, González M, Sanz MA, PETHEMA Group: Treatment with all-trans retinoic acid and anthracycline monochemotherapy for children with acute promyelocytic leukemia: a multicenter study by the PETHEMA Group. J Clin Oncol 2005, 23:7632-7640[http://jco.ascopubs.org/content/23/30/7632.long].

8. Chow J, Feusner J: Isolated central nervous system recurrence of acute promyelocytic leukemia in children. Pedia Blood Cancer 2009, 52:11-13 [http://www.ncbi.nlm.nih.gov/pubmed/18816805].

9. Avvisati G, Lo Coco F, Diverio D, Falda M, Ferrara F, Lazzarino M, Russo D, Petti MC, Mandelli F: AIDA (alltrans retinoic acid idarubicin) in newly diagnosed acute promyelocytic leukemia: a Gruppo Italiano Malattie Ematologiche Maligne dell'Adulto (GIMEMA) pilot study. Blood 1996, 88:1390-1398[http://www.ncbi.nlm.nih.gov/pubmed/8695858].

10. Sanz MA, Martín G, Rayón C, Esteve J, González M, Díaz-Mediavilla J, Bolufer P, Barragán E, Terol MJ, González JD, Colomer D, Chillón C, Rivas C, Gómez T, Ribera JM, Bornstein R, Román J, Calasanz MJ, Arias J, Alvarez C, Ramos F, Debén G: A modified AIDA protocol with anthracycline-based consolidation results in high antileukemic efficacy and reduced toxicity in newly diagnosed PML/RARalpha-positive acute promyelocytic leukemia. Blood 1999, 94:3015-3021 [http://bloodjournal.hematologylibrary. org/content/94/9/3015.long].

11. Bartel DP: MicroRNAs: genomics, biogenesis, mechanism, and function. Cell 2004, 116:281-297[http://www.ncbi.nlm.nih.gov/pubmed/14744438].

12. Ambros V: The functions of animal microRNAs. Nature 2004, 431:350-355 [http://www.nature.com/nature/journal/v431/n7006/full/nature02871.html].

13. Lim LP, Lau NC, Garrett-Engele P, Grimson A, Schelter JM, Castle J, Bartel DP, Linsley PS, Johnson JM: Microarray analysis shows that some microRNAs downregulate large numbers of target mRNAs. Nature 2005, 433:769-73[http://www.nature.com/nature/journal/v433/n7027/full/ nature03315.html].

14. Lu J, Getz G, Miska EA, Alvarez-Saavedra E, Lamb J, Peck D, SweetCordero A, Ebert BL, Mak RH, Ferrando AA, Downing JR, Jacks T, Horvitz HR, Golub TR: MicroRNA expression profiles classify human cancers. Nature 2005, 435:834-838[http://www.ncbi.nlm.nih.gov/pubmed/15944708].

15. Calin GA, Liu CG, Sevignani C, Ferracin M, Felli N, Dumitru CD, Shimizu M, Cimmino A, Zupo S, Dono M, Dell'Aquila ML, Alder H, Rassenti L, Kipps TJ, Bullrich F, Negrini M, Croce CM: MicroRNA profiling reveals distinct signatures in B cell chronic lymphocytic leukemias. Proc Natl Acad Sci USA 2004, 101:11755-11760[http://www.pnas.org/content/101/32/11755. long].

16. Calin GA, Ferracin M, Cimmino A, Di Leva G, Shimizu M, Wojcik SE, lorio MV, Visone R, Sever NI, Fabbri M, luliano R, Palumbo T, Pichiorri F, Roldo C, Garzon R, Sevignani C, Rassenti L, Alder H, Volinia S, Liu CG, Kipps TJ, Negrini $M$, Croce CM: A microRNA signature associated with prognosis and progression in chronic lymphocytic leukemia. N Engl J Med 2005, 353:1793-1801 [http://www.nejm.org/doi/full/10.1056/NEJMoa050995].

17. Garzon R, Volinia S, Liu CG, Fernandez-Cymering C, Palumbo T, Pichiorri F, Fabbri M, Coombes K, Alder H, Nakamura T, Flomenberg N, Marcucci G, Calin GA, Kornblau SM, Kantarjian H, Bloomfield CD, Andreeff M, Croce CM: MicroRNA signatures associated with cytogenetics and prognosis in acute myeloid leukemia. Blood 2008, 111:3183-3189[http://www.ncbi.nIm. nih.gov/pubmed/18187662].

18. Garzon R, Garofalo M, Martelli MP, Briesewitz R, Wang L, FernandezCymering C, Volinia S, Liu CG, Schnittger S, Haferlach T, Liso A, Diverio D, Mancini M, Meloni G, Foa R, Martelli MF, Mecucci C, Croce CM, Falini B: Distinctive microRNA signature of acute myeloid leukemia bearing cytoplasmic mutated nucleophosmin. Proc Natl Acad Sci USA 2008, 105:3945-3950[http://www.pnas.org/content/105/10/3945.long].

19. Jongen-Lavrencic M, Sun SM, Dijkstra MK, Valk PJ, Löwenberg B: MicroRNA expression profiling in relation to the genetic heterogeneity of acute myeloid leukemia. Blood 2008, 111:5078-5085[http://bloodjournal. hematologylibrary.org/content/111/10/5078.long].

20. Navarro A, Gaya A, Martinez A, Urbano-Ispizua A, Pons A, Balagué O, Gel B, Abrisqueta P, Lopez-Guillermo A, Artells R, Montserrat E, Monzo M: MicroRNA Expression Profiling in Classical Hodgkin Lymphoma. Blood 
2008, 111:2825-2832[http://bloodjournal.hematologylibrary.org/content/111/ 5/2825.long].

21. Fazi F, Racanicchi S, Zardo G, Starnes LM, Mancini M, Travaglini L, Diverio D, Ammatuna E, Cimino G, Lo-Coco F, Grignani F, Nervi C: Epigenetic silencing of the myelopoiesis regulator microRNA-233 by the AML1/ETO oncoprotein. Cancer Cell 2007, 12:457-466[http://www.cell.com/cancer-cell/ retrieve/pii/S1535610807002681].

22. Fazi F, Rosa A, Fatica A, Gelmetti V, De Marchis ML, Nervi C, Bozzoni I: A mini-circuitry comprising microRNA-223 and transcription factors NFI-A and C/EBPa regulates human granulopoiesis. Cell 2005, 123:819-831 [http://www.cell.com/retrieve/pii/S0092867405009773].

23. Garzon R, Pichiorri F, Palumbo T, Visentini M, Aqeilan R, Cimmino A, Wang H, Sun H, Volinia S, Alder H, Calin GA, Liu CG, Andreeff M, Croce CM: MicroRNA gene expression during retinoic acid-induced differentiation of human acute promyelocytic leukemia. Oncogene 2007, 26:4148-4157 [http://www.nature.com/onc/journal/v26/n28/full/1210186a.html].

24. Saumet $A$, Vetter $G$, Bouttier M, Portales-Casamar E, Wasserman WW, Maurin T, Mari B, Barbry P, Vallar L, Friederich E, Arar K, Cassinat B, Chomienne $C$, Lecellier $\mathrm{CH}$ : Transcriptional repression of microRNA genes by PML-RARA increases expression of key cancer proteins in acute promyelocytic leukemia. Blood 2009, 113:412-421 [http://bloodjournal. hematologylibrary.org/content/113/2/412.long].

25. De Marchis ML, Ballarino M, Salvatori B, Puzzolo MC, Bozzoni I, Fatica A: A new molecular network comprising PU.1, interferon regulatory factor proteins and miR-342 stimulates ATRA-mediated granulocytic differentiation of acute promyelocytic leukemia cells. Leukemia 2009, 23:856-862[http://www.nature.com/leu/journal/v23/n5/full/leu2008372a. html].

26. Zhang $H$, Luo $X Q$, Zhang $P$, Huang $L B$, Zheng $Y S$, Wu J, Zhou $H$, Qu LH, $\mathrm{Xu}$ L, Chen YQ: MicroRNA patterns associated with clinical prognostic parameters and CNS relapse prediction in pediatric acute leukemia. PLOS One 2009, 4:e7826[http://www.plosone.org/article/info\%3Adoi\%2F10.1371\% 2Fjournal.pone.0007826].

27. Chen C, Ridzon DA, Broomer AJ, Zhou Z, Lee DH, Nguyen JT, Barbisin M, Xu NL, Mahuvakar VR, Andersen MR, Lao KQ, Livak K, Guegler KJ: Real-time quantification of microRNAs by stem-loop RT-PCR. Nucleic Acids Res 2005, 33:e179[http://www.ncbi.nlm.nih.gov/pubmed/16314309].

28. Livak KJ, Schmittgen TD: Analysis of relative gene expression data using real-time quantitative PCR and the 2(-Delta Delta C(T)) Method. Methods 2001, 25:402-408[http://www.sciencedirect.com/science/article/pii/ S1046202301912629]

29. Lagos-Quintana M, Rauhut R, Yalcin A, Meyer J, Lendeckel W, Tuschl T: Identification of tissue-specific microRNAs from mouse. Curr Biol 2002, 12:735-739[http://www.ncbi.nlm.nih.gov/pubmed/12007417].

30. Galonek HL, Hardwick JM: Upgrading the BCL-2 network. Nat Cell Biol 2006, 8:1317-1319[http://www.nature.com/ncb/journal/v8/n12/full/ncb12061317.html].

31. Leu Jl, Dumont P, Hafey M, Murphy ME, George DL: Mitochondrial p53 activates Bak and causes disruption of a Bak-Mcl1 complex. Nat Cell Biol 2004, 6:443-450[http://www.nature.com/ncb/journal/v6/n5/full/ncb1123. $\mathrm{html]}$

32. Le MT, Teh C, Shyh-Chang N, Xie H, Zhou B, Korzh V, Lodish HF, Lim B: MicroRNA-125b is a novel negative regulator of p53. Genes Dev 2009, 23:862-876[http://genesdev.cshlp.org/content/23/7/862.long].

33. Iorio MV, Ferracin M, Liu CG, Veronese A, Spizzo R, Sabbioni S, Magri E, Pedriali M, Fabbri M, Campiglio M, Ménard S, Palazzo JP, Rosenberg A, Musiani P, Volinia S, Nenci I, Calin GA, Querzoli P, Negrini M, Croce CM: MicroRNA gene expression deregulation in human breast cancer. Cancer Res 2005, 65:7065-7070[http://www.ncbi.nlm.nih.gov/pubmed/16103053].

34. Visone $R$, Pallante $P$, Vecchione $A$, Cirombella $R$, Ferracin $M$, Ferraro $A$, Volinia S, Coluzzi S, Leone V, Borbone E, Liu CG, Petrocca F, Troncone G, Calin GA, Scarpa A, Colato C, Tallini G, Santoro M, Croce CM, Fusco A: Specific microRNAs are downregulated in human thyroid anaplastic carcinomas. Oncogene 2007, 26:7590-7595[http://www.nature.com/onc/ journal/v26/n54/full/1210564a.html].

35. Yang H, Kong W, He L, Zhao JJ, O'Donnell JD, Wang J, Wenham RM, Coppola D, Kruk PA, Nicosia SV, Cheng JQ: MicroRNA expression profiling in human ovarian cancer: miR-214 induces cell survival and cisplatin resistance by targeting PTEN. Cancer Res 2008, 68:425-433[http://cancerres. aacrjournals.org/content/68/2/425.long].
36. Nam EJ, Yoon H, Kim SW, Kim H, Kim YT, Kim JH, Kim JW, Kim S: MicroRNA expression profiles in serous ovarian carcinoma. Clin Cancer Res 2008, 14:2690-2695[http://www.ncbi.nlm.nih.gov/pubmed/18451233].

37. Wong TS, Liu XB, Wong BY, Ng RW, Yuen AP, Wei WI: Mature miR-184 as Potential Oncogenic microRNA of Squamous Cell Carcinoma of Tongue. Clin Cancer Res 2008, 14:2588-2592[http://clincancerres.aacrjournals.org/ content/14/9/2588.long].

38. Li W, Xie L, He X, Li J, Tu K, Wei L, Wu J, Guo Y, Ma X, Zhang P, Pan Z, Hu X, Zhao Y, Xie H, Jiang G, Chen T, Wang J, Zheng S, Cheng J, Wan D, Yang S, Li Y, Gu J: Diagnostic and prognostic implications of microRNAs in human hepatocellular carcinoma. Int J Cancer 2008, 123:1616-1622 [http://www.ncbi.nlm.nih.gov/pubmed/18649363].

39. Bousquet M, Quelen C, Rosati R, Mansat-De Mas V, La Starza R, Bastard C, Lippert E, Talmant P, Lafage-Pochitaloff M, Leroux D, Gervais C, Viguié F, Lai IL, Terre C, Beverlo B, Sambani C, Hagemeijer A, Marynen P, Delsol G, Dastugue N, Mecucci C, Brousset P: Myeloid cell differentiation arrest by miR-125b-1 in myelodysplasic syndrome and acute myeloid leukemia with the $\mathrm{t}(2 ; 11)(\mathrm{p} 21 ; \mathrm{q} 23)$ translocation. J Exp Med 2008, 205:2499-2506 [http://jem.rupress.org/content/205/11/2499.long].

40. Bousquet M, Harris MH, Zhou B, Lodish HF: MicroRNA miR-125b causes leukemia. Proc Natl Acad Sci USA 2010, 107:21558-21563[http://www.ncbi. nlm.nih.gov/pubmed/21118985].

41. Shi XB, Xue L, Yang J, Ma AH, Zhao J, Xu M, Tepper CG, Evans CP, Kung HJ, deVere White RW: An androgen-regulated miRNA suppresses Bak1 expression and induces androgen-independent growth of prostate cancer cells. Proc Natl Acad Sci USA 2008, 104:19983-19988[http://www. pnas.org/content/104/50/19983.long].

42. Zhou M, Liu Z, Zhao Y, Ding Y, Liu H, Xi Y, Xiong W, Li G, Lu J, Fodstad O, Riker Al, Tan M: MicroRNA-125b confers the resistance of breast cancer cells to paclitaxel through suppression of pro-apoptotic $\mathrm{BCl}-2$ antagonist killer 1 (Bak1) expression. J Biol Chem 2010, 285:21496-21507[http://www. ncbi.nlm.nih.gov/pubmed/20460378].

43. Schotte D, De Menezes RX, Akbari Moqadam F, Mohammadi Khankahdani L, Lange-Turenhout E, Chen C, Pieters R, Den Boer ML MicroRNAs characterize genetic diversity and drug resistance in pediatric acute lymphoblastic leukemia. Haematologica 2011, 96:703-711 [http://www.haematologica.org/cgi/content/full/96/5/703].

44. Li Z, Lu J, Sun M, Mi S, Zhang H, Luo RT, Chen P, Wang Y, Yan M, Qian Z, Neilly MB, Jin J, Zhang Y, Bohlander SK, Zhang DE, Larson RA, Le Beau MM, Thirman MJ, Golub TR, Rowley JD, Chen J: Distinct microRNA expression profiles in acute myeloid leukemia with common translocations. Proc Natl Acad Sci USA 2008, 105:15535-15540[http://www.pnas.org/content/105/ 40/15535.long].

doi:10.1186/1476-4598-10-108

Cite this article as: Zhang et al: Upregulation of microRNA-125b contributes to leukemogenesis and increases drug resistance in pediatric acute promyelocytic leukemia. Molecular Cancer 2011 10:108.

\section{Submit your next manuscript to BioMed Central and take full advantage of:}

- Convenient online submission

- Thorough peer review

- No space constraints or color figure charges

- Immediate publication on acceptance

- Inclusion in PubMed, CAS, Scopus and Google Scholar

- Research which is freely available for redistribution

Submit your manuscript at www.biomedcentral.com/submit
C Biomed Central 